Supporting Information Available

\title{
Synthesis and Shape Evolution of Monodisperse Basic Magnesium Carbonate Microspheres
}

\author{
Zhiping Zhang, Yajun Zheng, Jixiu Zhang, Qing Zhang, Jiping Chen,* \\ Zhongmin Liu and Xinmiao Liang *
}

Dalian Institute of Chemical Physics, Chinese Academy of Sciences, 457 Zhongshan Road, Dalian 116023, China, and Institute of Chemistry for Functionalized Materials, Department of Chemistry, Liaoning Normal University, Dalian 116029, China

Email: chenjp@dicp.ac.cn (J.Chen) and liangxm@dicp.ac.cn (X. Liang)

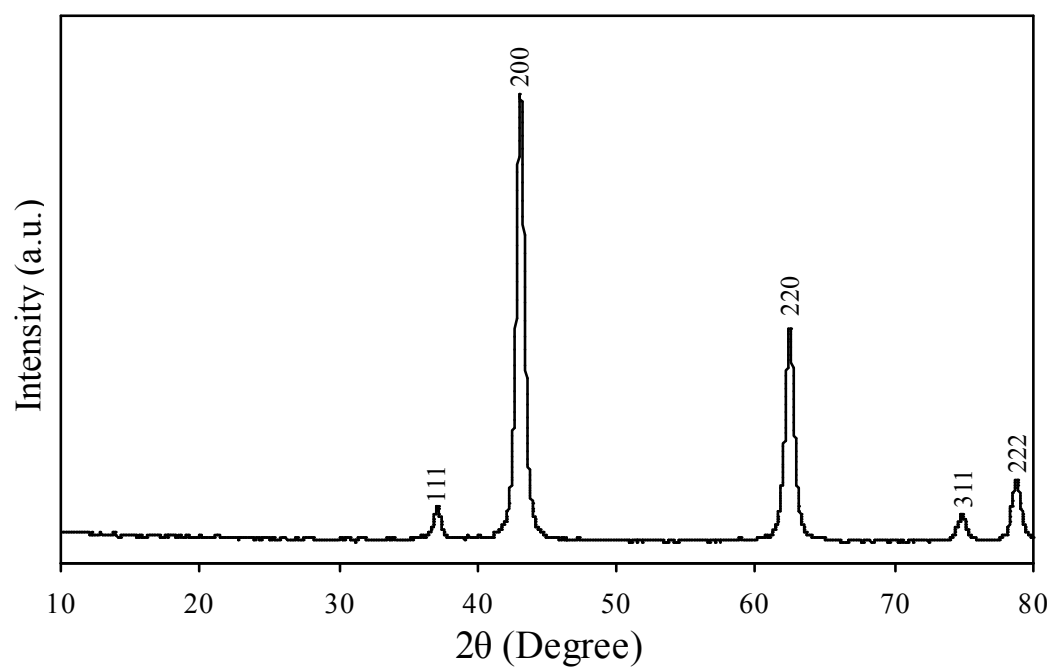

Figure SI-1. XRD patterns of the particles by calcination of spherical-like $\mathrm{Mg}_{5}\left(\mathrm{CO}_{3}\right)_{4}(\mathrm{OH})_{2} \cdot 4 \mathrm{H}_{2}$ Oprepared at $353 \mathrm{~K}$ with a stirring time of $0.5 \mathrm{~min}$.

The recorded XRD pattern of the sample from calcination of $\mathrm{Mg}_{5}\left(\mathrm{CO}_{3}\right)_{4}(\mathrm{OH})_{2} \cdot 4 \mathrm{H}_{2} \mathrm{O}$ is shown in Figure SI-1. The sharp diffraction peaks corresponding to the cubic $\mathrm{MgO}$ phase with the cell constant of $\mathrm{a}=4.21 \AA$ (JCPDS Card: 4-829) are observed, indicating the formation of pure $\mathrm{MgO}$ of high crystallinity. 


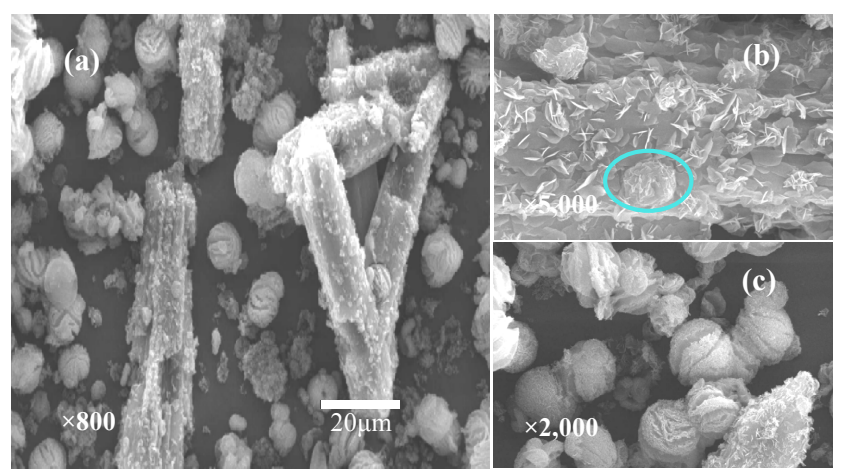

Figure SI-2. Representative SEM images of the particles prepared from a reaction time of 5 min at $353 \mathrm{~K}$ with a stirring time of $0.5 \mathrm{~min}$ and dried under the vacuum condition at $323 \mathrm{~K}$ for hours: (a) panoramic morphologies; (b) the magnification images of the column structure and (c) the spherical-like particles.
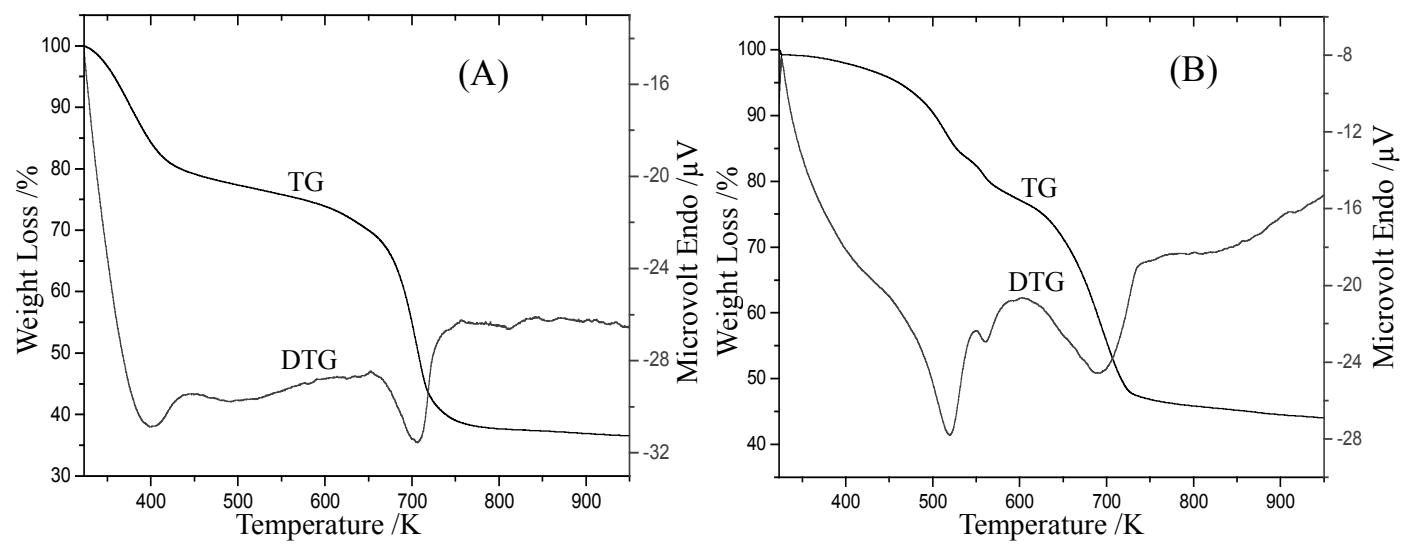

Figure SI-3. TG and DTG profiles of the particles (A) from a stirring time of 2 min at $313 \mathrm{~K}$ for $0 \mathrm{~min}$, and (B) the particles by adding the needlelike particles into $100 \mathrm{~mL}$ of double-deionized water with a temperature of $353 \mathrm{~K}$ for $25 \mathrm{~min}$.

As shown in Figure SI-3(A), the first weight loss in the range of $323-453 \mathrm{~K}$ is $22 \%$, which is due to the loss of absorbed water and water of crystallization. The second weight loss is only $4.5 \%$, observed in the range of $453-653 \mathrm{~K}$, which should be attributed to the decomposition of $\mathrm{Mg}(\mathrm{OH})_{2}$ to $\mathrm{MgO}$. The third weight loss (36\%) is observed at 653-823 $\mathrm{K}$, which is attributed to the decomposition of $\mathrm{MgCO}_{3}$ to $\mathrm{MgO}$.

For the sample by adding the needlelike particles into $100 \mathrm{~mL}$ of double-deionized water with a temperature of $353 \mathrm{~K}$ for $25 \mathrm{~min}$, the first weight loss in the range of $323-553 \mathrm{~K}$ is $17.1 \%$ as shown in Figure SI-3(B), which is due to the loss of absorbed 
water and water of crystallization. The second weight loss is only $4.7 \%$, observed in the range of 553-588 $\mathrm{K}$, which should be attributed to the decomposition of $\mathrm{Mg}(\mathrm{OH})_{2}$ to $\mathrm{MgO}$. The third weight loss $(34.2 \%)$ is observed at $588-918 \mathrm{~K}$, which is attributed to the decomposition of $\mathrm{MgCO}_{3}$ to $\mathrm{MgO}$.

After a calculation of these results, the sample from a stirring time of $2 \mathrm{~min}$ at 313 $\mathrm{K}$ for 0 min has a simple formula of $\left(\mathrm{MgCO}_{3}\right)_{0.8}\left(\left(\mathrm{Mg}(\mathrm{OH})_{2}\right)_{0.2} \cdot 1.3 \mathrm{H}_{2} \mathrm{O}\right.$. For the sample by adding the needlelike particles into $100 \mathrm{~mL}$ of double-deionized water with a temperature of $353 \mathrm{~K}$ for $25 \mathrm{~min}$, it has a formula of $\mathrm{Mg}_{5}\left(\mathrm{CO}_{3}\right)_{4}(\mathrm{OH})_{2} \cdot 4 \mathrm{H}_{2} \mathrm{O}$.

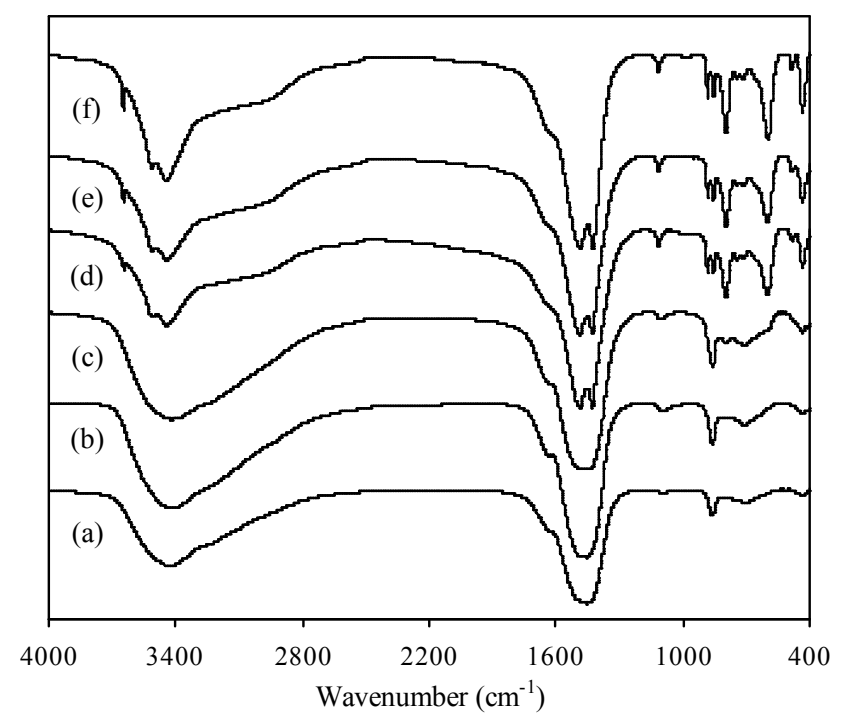

Figure SI-4 FT-IR spectra of the particles from various reaction times at $353 \mathrm{~K}$ with a stirring time of $0.5 \mathrm{~min}$ : (a) $2 \mathrm{~min}$; (b) 5 min; (c) $10 \mathrm{~min}$; (d) $20 \mathrm{~min}$; (e) $30 \mathrm{~min}$ and (f) $60 \mathrm{~min}$. 


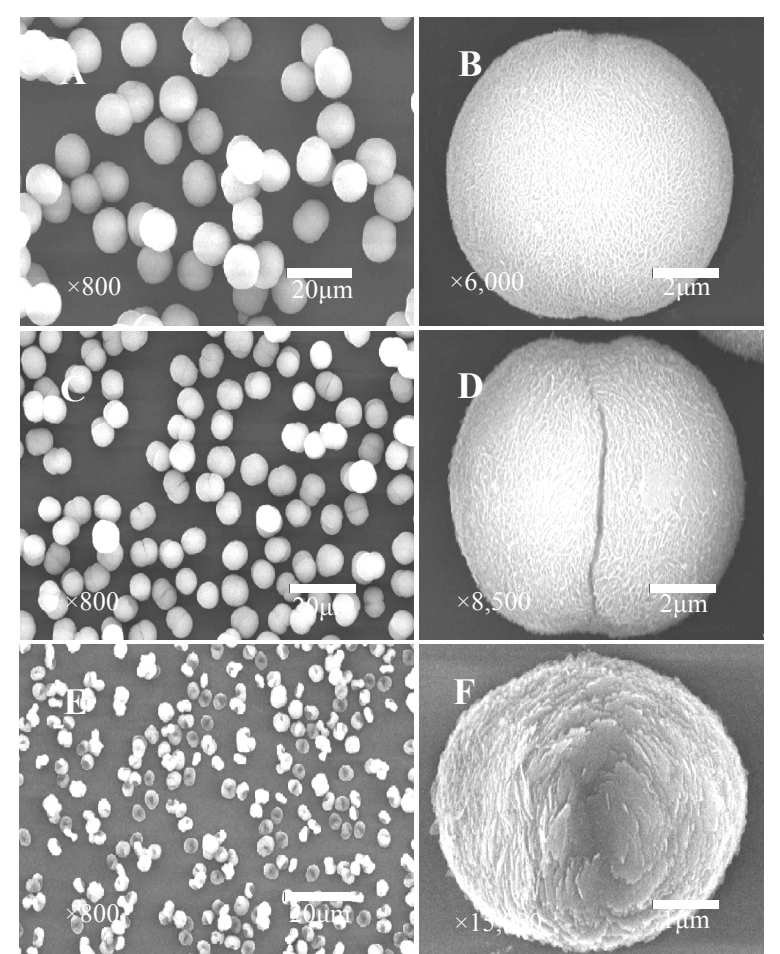

Figure SI-5. Representative SEM images of the particles

from various reaction temperatures with a stirring time of 1 min by different magnifications: (A) and (B) $333 \mathrm{~K}$, (C) and

(D) $343 \mathrm{~K}$, (E) and (F) $363 \mathrm{~K}$. 